\title{
The Construct Validity and Reliability of The Turkish Version of Self-consciousness Scale
}

\author{
Ahmet AKIN* Ramazan ABACI** Ümran ÖVEÇ ${ }^{* * *}$
}

\begin{abstract}
The aim of this study is to adapt the Selfconsciousness Scale (Mittal \& Balasubramanian, 1987) to Turkish and to examine its psychometric properties. Participants were 740 university students from Sakarya University. In this study firstly, the language equivalency between English and Turkish forms were tested. After that exploratory factor analysis, confirmatory factor analysis, Internal consistency coefficients, and test-retest reliabilities, corrected item-total correlations and t-tests between items' means of upper $27 \%$-lover $27 \%$ points of the Turkish form were examined. Results showed that the scale called Self-consciosness Scale as a valid and reliable instrument can be used in the fields of psychology and education.
\end{abstract}

Key Words: Self-consciousness, Validity, Reliability, Confirmatory factor analysis

\footnotetext{
* Arş. Gör. Sakarya Üniversitesi Eğitim Fakültesi Eğitim Bilimleri Bölümü, aakin@sakarya.edu.tr

** Prof. Dr. Sakarya Üniversitesi Eğitim Fakültesi Eğitim Bilimleri Bölümü, rabaci@sakarya.edu.tr

*** Uzman Psikolojik Danışman, uovec@sakarya.edu.tr
} 


\section{SUMMARY}

Purpose and significance: The concept of self-consciousness, taken as being the tendency to direct attention toward aspects of the self, has been linked with very different areas of psychological functioning and are believed to play significant roles in the everyday life of the individual. Based on private self-consciousness, public self-consciousness, and social anxiety components, Fenigstein et al. (1975) developed the Self-consciousness Scale (SCS). Later, Mittal and Balasubramanian (1987) performed an exhaustive analysis and concluded that private self-consciousness was made up of selfreflectiveness and internal state awareness, while public self-consciousness included style consciousness and appearance consciousness. Thus they suggested a 5 factor model for the SCS. The aim of this research is to adapt SCS (Mittal \& Balasubramanian, 1987) to Turkish and to examine its psychometric properties.

Method: Participants were 740 university students from Sakarya University. In this study, language equivalence between English and Turkish forms of the SCS and internal consistency coefficients, and test-retest reliabilities, item-total correlations and t-tests between items' means of upper 27\%-lover 27\% points of the Turkish form were examined. Data were analyzed using LISREL 8.54 and SPSS 11.5 package programs.

Results: Language equivalence study demonstrated that correlations between Turkish and English forms of SCS were quite high (.93 for selfreflectiveness, .87 for internal state awareness, .96 for style consciousness, .91 for appearance consciousness, and .93 for social anxiety). Results of exploratory factor analysis showed that the 19 items loaded on five factors like original form. The amount of total variance explained by five factors was $68 \%$. Confirmatory factor analysis demonstrated that the model was well fit. Also, Chi-Square value $\left(x^{2}=330.91, \mathrm{~N}=740, \mathrm{sd}=140, \mathrm{p}=0.00\right)$ which calculated for the adaptation of the model was significant. The goodness of fit index values of the model were RMSEA $=0.047$, NFI $=0.95, \mathrm{CFI}=0.97$, $\mathrm{IFI}=0.97$, RFI $=0.96, \mathrm{GFI}=0.95$, and AGFI $=0.93$. The internal consistency values calculated for the 5 factors of the scale vary between .84 and .91 . The test-retest reliability scores were found as $.94, .92, .96, .91$, and .94 , for the 5 factors, respectively, and the corrected item-total correlations of SCS ranged from .40 to .70. Lastly, for each factor and each item, the differences between mean scores of upper $27 \%$ and lover $27 \%$ groups were significant $(\mathrm{p}<.001)$.

Discussion and Conclusions: In this study, factor structure of the Turkish version of SCS was examined via exploratory and confirmatory 
factor analyses. The CFA results showed that the factorial model of SCS that consists of 5 factors were at an acceptable degree of goodness of fit for Turkish sample. The internal consistency, re-test, coefficients of the factors of SCS showed acceptable reliability. The results of item analysis of scale showed that items distinguished individuals sufficiently in terms of relevant features of items. According to these findings SCS can be termed as a valid and reliable instrument that could be used in fields of education and psychology. 


\title{
Öz-bilinç Ölçeği’nin Türkçe Formunun Yapı Geçerliği ve Güvenirliği
}

\author{
Ahmet AKIN* Ramazan ABACI** Ümran ÖVEÇ ${ }^{* * *}$
}

ÖZ. Bu araştırmanın amacı Öz-bilinç Ölçeği’ni (Mittal \& Balasubramanian, 1987) Türkçeye uyarlamak ve ölçeğin psikometrik özelliklerini incelemektir. Araştırma Sakarya Üniversitesi Eğitim Fakültesi'nde öğrenim gören 740 üniversite öğrencisi üzerinde yürütülmüştür. Çalışmada öncelikle ölçeğin dilsel eşdeğerliği incelenmiş ve yüksek düzeyde eşdeğerliğe sahip olduğu görülmüştür. Daha sonra açımlayıcı faktör analizi, doğrulayıcı faktör analizi, iç tutarll11k ve test-tekrar test güvenirlikleri, madde toplam korelasyonu ve $t$ testi kullanılarak üst \% 27 ile alt \% 27 grupların madde ortalamaları arasındaki farkların anlamlılığı incelenmiştir. Geçerlik ve güvenirlik çalışmalarından elde edilen bulgular ölçeğin orijinal formunda olduğu gibi 5 alt ölçekten oluştuğunu ve yüksek düzeyde güvenirlik katsayılarına sahip olduğunu ortaya koymuştur. Sonuç olarak, Öz-bilinç Ölçeği'nin Türkçe formunun eğitim ve psikoloji alanında kullanılabilecek geçerli ve güvenilir bir araç olduğu saptanmıştır.

Anahtar Kelimeler: Öz-bilinç, Geçerlik, Güvenirlik, Doğrulayıcı faktör analizi

\footnotetext{
* Arş. Gör. Sakarya Üniversitesi Eğitim Fakültesi Eğitim Bilimleri Bölümü, aakin@sakarya.edu.tr

*** Prof. Dr. Sakarya Üniversitesi Eğitim Fakültesi Eğitim Bilimleri Bölümü, rabaci@sakarya.edu.tr

*** Uzman Psikolojik Danışman, uovec@sakarya.edu.tr
} 


\section{GíRís}

Genel olarak bireyin benliğinin çeşitli boyutlarına ve çevresine yönelik ilgi, dikkat ve farkındalığını ifade eden öz-bilinç kavramının bireylerin duygu, düşünce ve davranışları üzerinde önemli etkileri vardır. Bu kavram psikolojide birçok araştırmaya konu olmuş ve araştırmacıları öz-bilinç ile birçok değişken arasındaki ilişkileri incelemeye sevk etmiştir. Öz-bilinç yapısını inceleyen ilk araştırmacılar olan Fenigstein, Scheier ve Buss (1975), bireylerin genellikle dikkat açısından farklı noktalara odaklandıklarını, bazı bireylerin içsel duygu ve düşünceleriyle ilgilenirken, bazılarının daha çok dış çevre ve diğer bireylere karşı duyarlı olduklarını ifade etmiştir.

Fenigstein ve diğerleri (1975) öz-odaklılık eğiliminin kararlı bir özellik olduğunu ve özel öz-bilinç, genel öz-bilinç ve sosyal anksiyete şeklinde üç boyuta ayrıldığını belirtmiştir. Özel öz-bilinç; bireyin özel duygu ve inançları gibi diğerleri tarafindan kolayca ulaşılamayan gizil ve kişisel yönleri üzerinde derin biçimde düşünmesi ve bu yönlerine ilişkin farkındalık geliştirmesi eğilimini ifade eder. Genel öz-bilinç; bireyin bir sosyal obje olarak kendi hakkında düşünmesi ve fiziksel görünümü, tutum ve davranıșları gibi diğerlerine de açık olan yönleri hakkında farkındalık sağlamasıyla ilişkilidir. Son olarak genel öz-bilinçten kaynaklanan sosyal anksiyete ise, bireyin sosyal ortamlarda diğerleri tarafindan nasıl değerlendirildiğine yönelik kaygı yaşamasıdır (Nystedt \& Ljungberg, 2002).

Bu üç unsuru temel alarak Fenigstein ve diğerleri (1975), 10'u özel özbilinç, 7'si genel öz-bilinç ve 6's1 sosyal anksiyete alt ölçeklerine ait olmak üzere toplam 23 maddeden oluşan ve 5'li likert tipi bir ölçme aracı olan Özbilinç Ölçeği'ni geliştirmiştir. Her bir madde " 0 ”dan (hiç uygun değil) "4"e (tamamen uygun) doğru siralanan 5'li likert tipi bir derecelendirme ölçeği şeklinde yazılmıştır. Bu ölçek pek çok araştırmada kullanılmış (Buss, 1980; Carver \& Scheier, 1981; Scheier \& Carver, 1985) ve ölçeğin yap1 geçerliği farklı kültürlerde kanitlanmıştır (Banos, Belloch, \& Perpina, 1990; Heineman, 1979; Piliavin \& Charng, 1988).

Üç boyutlu yaklaşım ve bu üç alt ölçeğin yordayıcı geçerlikleri birçok çalışmada (Bernstein, Teng, \& Garbin, 1986; Britt, 1992; Fenigstein ve diğerleri, 1975; Scheier \& Carver, 1977; Scheier, Buss, \& Buss, 1978; Turner, 1978) desteklenmiş ve Almanya (Heineman, 1979), Brezilya (Texiera \& Gomes, 1995), Çin (Shek, 1994), Estonya (Realo \& Allik, 1998), Hollanda (Vleeming \& Engles, 1981), İspanya (Banos ve diğerleri, 1990), İsveç (Nystedt \& Smari, 1989), İsviçre (Grob, 1995), İtalya (Comunian, 1994), Polonya (Piliavin \& Charng, 1988) ve Suudi Arabistan (Bendania \& Abed, 1997) gibi birçok ülkenin dil ve kültürüne uyarlanmıştır.

Bununla birlikte araştırmalar, öz-bilincin hem birçok psikolojik iyi olma göstergeleriyle hem de çeşitli psikopatolojik durumlarla ilişkili olduğunu 
göstermiştir. Örneğin yüksek düzeyde öz-bilince sahip olan bireylerin, daha net bir öz-şemaya ve daha doğru öz-bilgiye sahip olduğu öne sürülmüştür (Lindwall, 2004). Böylelikle bu bireylerin kişisel özelliklerine uygun biçimde davranma olasılıklarının daha yüksek olduğu belirtilmiştir (Baumeister \& Trice, 1988; Carver \& Scheier, 1978). Aynı zamanda bazı çalışmalar, yüksek düzeyde öz-bilinç ile depresyon, anksiyete, sınav kaygısı ve alkol kullanımı gibi çeşitli psikolojik rahatsızlıklar arasında pozitif ilişki bulmuştur (Ingram, 1990).

Öz-bilinç Ölçeği'ni kullanan araştırmalardan elde edilen çelişkili sonuçlar araştırmacıları bu üç faktörün geçerliğini incelemeye sevk etmiş ve psikometrik özelliklerini inceleyen araştırmacılar ölçeğin faktör yapısında bazı sorunlar olduğunu öne sürmüştür. Burnkrant ve Page (1984) ölç eğin 23 maddesi için yaptıkları doğrulayıcı faktör analizinde 4 faktör bulmuş ve araştırmadan elde edilen bulgular, özel öz-bilinci kendini düşünme ve içsel öz-farkındalık şeklinde iki alt boyuta ayıran modeli desteklemiştir. Bu araştırmada özel öz-bilinç ve genel öz-bilinç alt ölçeklerinden iki, sosyal anksiyete alt ölçeğinden bir madde faktör yükleri düşük olduğu için ölçekten çıkarılmıştır.

Birinci boyut olan kendini düşünme, bireyin çocukluk deneyimlerini de içeren geçmiş yaşantıları ve davranışları hakkında düşünmesi, hayal kurması ve kendini değerlendirmesi eğilimi olarak tanımlanabilir. İkinci boyut olan içsel öz-farkındalık ise, bireyin mutluluk, üzüntü gibi duygusal durumlarına iliş̧in daha objektif ve pozitif bir farkındalığa sahip olmasını ifade eder (Anderson, Bohon, \& Berrigan, 1996; Burnkrant \& Page, 1984; Chang, 1998; Creed \& Funder, 1998; Mittal \& Balasubramanian, 1987; Piliavin \& Charng, 1988).

Öz-bilinçle çeşitli değişkenler arasındaki ilişkileri inceleyen araştırmalardan elde edilen çelişkili sonuçlar, daha çok özel öz-bilinç alt ölçeğinin iki alt boyutu olan kendini düşünme ve içsel öz-farkındalığın psikolojik sağlık açısından birbirine zit olmasından kaynaklanmaktadır (Burnkrant \& Page, 1984; Mittal \& Balasubramanian, 1987). İçsel özfarkındalık psikolojik uyumla daha fazla ilişkiliyken (Watson \& Biderman, 1993; Watson, Milliron, \& Morris, 1995) kendini düşünme alt ölçeği daha çok psikolojik sorunlarla ilişkili bulunmuştur (Watson, Hickman, Morris, Stutz, \& Whiting, 1994; Watson, Morris, Ramsey, Hickman, \& Waddell, 1996).

Bazı araştırmalarda ise kendini düşünme alt boyutunun depresyon, anksiyete ve sosyal anksiyete ile pozitif, içsel öz-farkındalığın ise bu değişkenlerle negatif ilişkili olduğu görülmüştür (Anderson ve diğerleri, 1996; Watson \& Biderman, 1993; Watson ve diğerleri, 1996). Ayrica bir araştırmada utangaçlık ve suçluluk duygusu ile kendini düşünme alt boyutu 
arasında pozitif, aynı değişkenlerle içsel öz-farkındalık alt boyutu arasında negatif ilișki bulunmuștur (Watson ve diğerleri, 1996). Bu tutarsız sonuçların yol açtığı araştırmalar özel öz-bilincin tek boyutlu olmadığını ve iki alt boyuta sahip olduğunu göstermiştir (Burnkrant \& Page, 1984; Mittal \& Balasubramanian, 1987; Piliavin \& Charng, 1988).

Öz-bilinç Ölçeği’nin (Fenigstein ve diğerleri, 1975) faktör yapısı ve psikometrik özelliklerinin incelendiği diğer bir çalışmada Mittal ve Balasubramanian (1987), özel öz-bilincin Burnkrant ve Page'in (1984) önerdiği gibi iki alt boyuta sahip olduğu sonucunu elde etmiştir. Ancak bu araştırmada özel öz-bilinç alt ölçeğine ait maddeler Burnkrant ve Page'in (1984) elde ettiği maddelerden farklıdır. Ayrıca bu araştırmacılar genel özbilincin de stil bilinçliliği ve görünüm bilinçliliği olarak iki alt boyuta ayrılabileceğini savunarak, Öz-bilinç Ölçeği için beş faktörlü bir model öne sürmüşlerdir. Stil bilinçliliği; bireyin davranış stilleriyle ilişkili eğilimlerini ve diğerlerine sunmak istediği belli bir imaja yönelik ilgisini ifade ederken, görünüm bilinçliliği; bireyin fiziksel çekiciliğine ilişkin eğilimlerini ve fiziksel görünümü hakkında sahip olduğu farkındalığını yansıtmaktadır (Nystedt \& Ljungberg, 2002). Yapilan analizler sonucunda, sosyal anksiyete alt ölçeğine ait 12. ve 23. maddeler güvenirlik katsayıları düşük olduğu için, özel öz-bilinç alt ölçeğine ait 7. ve 9. maddeler ise herhangi bir alt ölçekte uyum vermediği için ölçekten çıkarılmıştır. Sonuç olarak ikisi özel öz-bilinç (kendini düşünme ve içsel öz-farkındalık), ikisi genel öz-bilinç (stil bilinçliliği ve görünüm bilinçliliğii) ve biri de sosyal anksiyete alt ölçeklerine ait olmak üzere toplam 5 faktörlü ve 19 maddelik bir ölçme aracı elde edilmiştir (Mittal \& Balasubramanian, 1987).

Genel öz-bilincin iki alt boyutu arasındaki ilişkileri ve onların çeşitli psikolojik ve psikolopatolojik göstergelerle bağlantılarını belirlemek amacıyla birçok çalışma yapılmıştır (Anderson ve diğerleri, 1996; Conway \& Giannopoulos, 1992; Conway, Giannopoulos, Csank, \& Mendelson, 1993; Creed \& Funder, 1998; Lennox, Welch, Wolfe, Zimmerman, \& Dixon, 1987; Piliavin \& Charng, 1988; Watson ve diğerleri, 1994, 1996). Bu çalışmalarda stil bilinçliliğinin, görünüm bilinçliliğine göre uyumsuzlukla daha fazla ilişkili olduğu görülmüştür (Cheek \& Briggs, 1982). Aynı zamanda stil bilinçliliği sosyal arzu edilebilirlik ile pozitif, görünüm bilinçliliği ise negatif ilişkili bulunmuştur (Watson ve diğerleri, 1995).

$\mathrm{Bu}$ araştırmanın amacı Fenigstein ve diğerleri (1975) tarafından geliştirilen ve Mittal ve Balasubramanian (1987) tarafindan revize edilen Özbilinç Ölçeği'ni Türkçeye uyarlamak ve ölçeğin geçerlik ve güvenirlik analizlerini yapmaktır. 


\section{YÖNTEM}

\section{Araştırma Grubu}

$\mathrm{Bu}$ araştırma Sakarya Üniversitesi Eğitim Fakültesi'nin çeşitli bölümlerinde öğrenim gören 740 üniversite öğrencisi üzerinde yürütülmüştür. Öğrencilerin 147 'si rehberlik ve psikolojik danışmanlık 183 'ü sosyal bilgiler öğretmenliği, 115'i bilgisayar ve öğretim teknolojileri öğretmenliği, 133'ü okul öncesi öğretmenliği ve 162'si fen bilgisi öğretmenliği bölümlerinde öğrenim görmektedir. Araştırma grubunun 396's1 (\%54) erkek ve 344'ü (\%46) kız öğrenciden oluşmaktadır. Büyük bir çoğunluğu 18 ile 22 yaşları arasında olan öğrencilerin yaş ortalaması 20'dir. Ayrıca test-tekrar test güvenirliği için, 205 kişilik bir gruba ölçek 21 gün arayla tekrar uygulanmıştır. Ölçeğin dilsel eşdeğerlik çalışması ise Sakarya ve Kocaeli'de görev yapan 175 İngilizce öğretmeni üzerinde yürütülmüştür.

\section{İşlem}

Geçerlik ve güvenirlik analizlerine başlamadan önce, ölçek üç aşamadan oluşan bir süreçte Türkçeye çevrilmiştir. İlk aşamada ölçek yüksek lisans ve doktorasını yurtdışında yapmış 4 öğretim üyesi tarafından önce İngilizceden Türkçeye çevrilmiş, bir hafta aradan sonra ise Türkçe formlar tekrar İngilizceye çevrilerek iki formun tutarlılığı dil ve gramer açısından incelenmiş ve denemelik Türkçe form elde edilmiştir. İkinci aşamada Türkçe form psikolojik danışmanlık ve rehberlik alanında yüksek lisans yapan 11 öğrenciye uygulanmış ve anlaşılmayan veya birden fazla anlam içeren ifadeleri belirlemeleri istenmiştir. $\mathrm{Bu}$ uygulama sonucunda katılımcıların yarıdan fazlasının düzeltilmesi gerektiğini düşündüğü ifadeler yeniden gözden geçirilerek, gerekli düzenlemeler yapılmıştır. Üçüncü aşamada, Türkçe form psikolojik danışmanlık ve rehberlik ve ölçme değerlendirme anabilim dallarında görev yapan 7 öğretim görevlisi tarafından tartışılmış ve son düzenlemeler yapılarak ölçek uygulamaya hazır hale getirilmiştir. Daha sonra ise 19 madde "0" dan (hiç uygun değil) " 4 "e (tamamen uygun) doğru sıralanan 5'li likert tipi bir derecelendirme ölçeği şeklinde, orijinal formdaki sıralamaya uygun olarak yazılarak, araştırma grubuna uygulanmış ve elde edilen veriler üzerinde geçerlik ve güvenirlik analizleri yapılmıştır. $\mathrm{Bu}$ araştırmada ölçeğin dilsel eşdeğerlik, yapı geçerliği, madde analizi ve güvenirlik çalışmaları olarak iç tutarlılık ve test tekrar test güvenirlikleri incelenmiştir. Ölçeğin geçerlik ve güvenirlik analizleri SPSS 11.5 ve LISREL 8.54 programları ile yapılmıştır. 


\section{BULGULAR}

\section{Dilsel Eşdeğerlik}

Öz-bilinç Ölçeği'nin dilsel eşdeğerlik çalışmasında ölçeğin orijinal formu (İngilizce form) ile Türkçe formu 175 İngilizce öğretmenine uygulanmış ve bu iki formdan elde edilen puanlar arasındaki korelasyon ölçeğin dilsel eşdeğerlik katsayısı olarak alınmıştır. $\mathrm{Bu}$ uygulamada öğretmenlere önce Türkçe formlar daha sonra ise İngilizce formlar verilmiştir. Ölçeğin Türkçe ve İngilizce formlarından elde edilen puanlar arasındaki korelasyon katsayılarına ilişkin bulgular Tablo 1'de verilmiştir.

Tablo 1. Öz-bilinç Ölçeği’nin Ingilizce ve Türkçe formlarından elde edilen puanlar arasındaki korelasyonlar

\begin{tabular}{lllll}
\hline Faktör & Form & $\bar{X}$ & Ss & $r$ \\
\hline \multirow{2}{*}{ Kendini düşünme } & İngilizce form & 15.24 & 2.97 & \multirow{2}{*}{.93} \\
& Türkçe form & 14.64 & 2.91 & \\
\multirow{2}{*}{ İçel öz-farkındalık } & İngilizce form & 14.17 & 3.73 & \multirow{2}{*}{.87} \\
& Türkçe form & 10.14 & 2.97 & \\
Stil bilinçliliği & İngilizce form & 7.89 & 2.44 & \multirow{2}{*}{.96} \\
& Türkçe form & 15.53 & 3.34 & \\
Görünüm bilinçliliği & İngilizce form & 14.76 & 3.18 & \multirow{2}{*}{.91} \\
& Türkçe form & 14.13 & 4.08 & \\
Sosyal anksiyete & İngilizce form & 10.08 & 3.11 & \multirow{2}{*}{.93} \\
\hline
\end{tabular}

Tablo 1 incelendiğinde ölçeğin orijinal formu ile Türkçe formundan elde edilen puanlar arasındaki korelasyon katsayılarının kendini düşünme alt boyutu için .93, içsel öz-farkındalık için .87, stil bilinçliliği için .96, görünüm bilinçliliği için .91 ve sosyal anksiyete için .93 olduğu görülmektedir. Bu sonuçlar ölçeğin İngilizce ve Türkçe formları arasındaki tutarlı1ığın oldukça yüksek olduğunu göstermektedir.

\section{Yapı Geçerliği}

Açımlayıcı Faktör Analizi. Araştırmada Öz-bilinç Ölçeği'nin orijinal formunun Türk öğrenciler üzerindeki yapısını açığa çıkarmak amacıyla açımlayıcı faktör analizi (AFA) kullanılmıştır. AFA çok sayıda değişkenden (maddeden) bu değişkenlerin birlikte açıklayabildikleri az sayıda tanımlanabilen anlamlı yapılara ulaşmayı hedefler. Faktör analizi sonuçlarını değerlendirmede temel ölçüt, değişkenlerle faktörler arasındaki korelasyonlar olarak yorumlanabilen faktör yükleridir. Faktör yüklerinin yüksek olması, değişkenin söz konusu faktör altında yer alabileceğinin bir göstergesi olarak görülür (Büyüköztürk, 2004). Bu çalışmada faktör yüklerinin yeterli görülmesi için genelde yapıldığ 1 gibi ölçüt olarak .30 alınmıştır. AFA'da öncelikle bütün maddeler arasında korelasyon matrisi 
incelenerek, önemli oranda manidar korelasyonların olup olmadığına bakılmış ve faktör analizinin yapılabilmesine uygunluk gösterir nitelikte manidar ilişkilerin olduğu görülmüştür. Daha sonra örneklem uygunluğu (sampling adequacy) ve Barlett Sphericity testleri gerçekleştirilmiştir. Verilerin faktör analizine uygunluğu için KMO .60'dan yüksek ve Barlett testinin anlamlı çıkması gerekmektedir (Büyüköztürk, 2004). Bu çalışmada KMO Örneklem Uygunluk katsayıs1 .76, Barlett Sphericity testi $\chi^{2}$ değeri ise $8606,693(\mathrm{p}<.001)$ olarak bulunmuştur. Bu değerler verilerin faktör analizi için uygun olduğunu göstermektedir.

Öz-bilinç Ölçeği'nin orijinal formu beş faktörden oluştuğu için AFA'da temel bileşenler tekniği ile oblik döndürme faktör çözümlemesi sonuçları beş faktörlülükle sınırlandırılmıştır. Bir ölçeğin faktörleri arasında ilişkisizlik (orthogonality) varsa varimax döndürme tekniği, faktörler arasında sürekli bir ilişki dizisi varsa genellikle oblik döndürme kullanılır (Tabachnick \& Fidell, 1996). Ölçeğin faktörleri arasında ilişki olduğu için bu araştırmada oblik döndürme tekniği kullanılmıştır. Yapılan analiz sonucunda toplam varyansın \%68'ini açıklayan ve maddelerinin tamamıla orijinal formdaki alt boyutlarında yer aldığ 5 faktörlü bir yapı ortaya çıkmıştır. Ayrıca tüm maddelerin faktör yükleri .30'dan yüksek olduğu için ölçekten herhangi bir maddenin çıkarılması gerekmemiştir. Türkçe formun faktör yapısına ilişkin bilgiler Tablo 2'de görülmektedir.

Tablo 2. Öz-bilinç Ölçeği faktör yükleri

\begin{tabular}{|c|c|c|c|c|c|}
\hline \multirow[b]{2}{*}{ Madde No } & \multicolumn{2}{|c|}{ 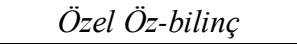 } & \multicolumn{2}{|c|}{ Genel Öz-bilinç } & \multirow[b]{2}{*}{$\begin{array}{c}\text { Sosyal } \\
\text { Anks. }\end{array}$} \\
\hline & $\begin{array}{l}\text { Kendini } \\
\text { düşün. }\end{array}$ & $\begin{array}{l}\text { İçsel Öz- } \\
\text { far. }\end{array}$ & $\begin{array}{c}\text { Stil } \\
\text { bilinç. }\end{array}$ & $\begin{array}{l}\text { Görün. } \\
\text { bilinç. }\end{array}$ & \\
\hline 18 & .87 & & & & \\
\hline 1 & .76 & & & & \\
\hline 15 & .74 & & & & \\
\hline 5 & .57 & & & & \\
\hline 3 & & .86 & & & \\
\hline 22 & & .74 & & & \\
\hline 20 & & .46 & & & \\
\hline 13 & & .35 & & & \\
\hline 6 & & & .86 & & \\
\hline 2 & & & .70 & & \\
\hline 19 & & & .67 & & \\
\hline 14 & & & .56 & & \\
\hline 11 & & & & .84 & \\
\hline 21 & & & & .61 & \\
\hline 17 & & & & .59 & \\
\hline 4 & & & & & .76 \\
\hline 8 & & & & & .76 \\
\hline 16 & & & & & .70 \\
\hline 10 & & & & & .40 \\
\hline $\begin{array}{c}\text { Açık. Var. } \\
\% 68.39\end{array}$ & $\% 31.46$ & $\% 14.44$ & $\% 11.62$ & $\% 5.71$ & $\% 5.16$ \\
\hline
\end{tabular}


Tablo 2'de görüldüğü gibi Öz-bilinç Ölçeği'nin Türkçe formu orijinal formda olduğu gibi ikisi özel öz-bilinç, ikisi genel öz-bilinç ve birisi ise sosyal anksiyete alt boyutlarına ait olmak üzere beş alt ölçekten oluşmaktadır. Özel öz-bilinç boyutu altında yer alan alt ölçeklerden birisi olan kendini düşünmeye ait maddeler bireyin geçmiş yaşantıları ve davranışları hakkında düşünmesi, hayal kurması ve kendini değerlendirmesiyle ilişkilidir. 4 maddeden oluşan kendini düşünme alt boyutu, toplam varyansın \%31.46'sını açıklamakta ve faktör yükleri .57 ile .87 arasında değişmektedir. $\mathrm{Bu}$ alt ölçekteki maddelere örnek olarak "kendim hakkında çok düşünürüm” verilebilir.

İkinci alt ölçek olan içsel öz-farkındalık ise, bireylerin duygusal durumlarına ilişkin daha objektif ve pozitif bir farkındalığa sahip olmasına yönelik maddeler içermektedir. 4 maddeden oluşan bu alt ölçek toplam varyansın \%14.44'ünü açıklamakta ve maddelerin faktör yükleri .35 ile .86 arasında değişmektedir. "Duygularımdaki değişikliklere karşı dikkatliyimdir" bu maddelere örnek olarak gösterilebilir.

Genel öz-bilinç boyutu altında ise stil bilinçliliği ve görünüm bilinçliliği alt ölçekleri yer almaktadır. Stil bilinçliliği; bireyin davranış stillerine ilişkin eğilimlerini ve diğerlerine sunmak istediği belli bir imaja yönelik ilgisini ölçmeye ilişkin maddeler içermektedir. 4 maddeden oluşan ve toplam varyansın \%11.62'sini açıklayan, bu alt ölçekteki maddelerin faktör yükleri .56 ile .86 arasında değişmektedir. Bu alt ölçekte yer alan maddelere örnek olarak "kendimi diğer insanlara nasıl sunacağıma ilişkin kaygı yaşarım" gösterilebilir.

Görünüm bilinçliliği alt ölçeği 3 maddeden oluşmakta ve toplam varyansın \%5.71'ini açıklamaktadır. Bu alt ölçekteki maddeler bireyin fiziksel çekiciliğine ilişkin eğilimlerini ve fiziksel görünümü hakkında sahip olduğu farkındalığını yansıtmaktadır. Faktör yükleri .59 ile .84 arasında değişen maddelere örnek olarak "evden ayrılmadan önce yaptığım en son şeylerden birisi aynaya bakmaktır" gösterilebilir.

Son alt ölçek olan sosyal anksiyete 4 maddeden oluşmakta ve toplam varyansın \%5.16'sını açıklamaktadır. Bu alt ölçekte yer alan maddeler bireyin sosyal ortamlarda diğerleri tarafından nasıl değerlendirildiğine yönelik kaygı yaşamasıyla ilişkilidir. Faktör yükleri .40 ile .76 arasında sıralanan bu 4 maddeye örnek olarak "yeni ortamlara katıldığımda utangaçlığımı yenmem zaman alır" gösterilebilir. Ölçeğin faktör yükleri ve açıkladıkları varyans oranlarının yanı sıra, alt ölçekler arasındaki korelasyonlar da incelenmiştir. Alt ölçeklere ilişkin korelasyon katsayıları Tablo 3'te verilmiştir. 


\begin{tabular}{|c|c|c|c|c|c|}
\hline Faktör & $\begin{array}{c}\text { Kendini } \\
\text { düşünme }\end{array}$ & $\begin{array}{c}\text { İçsel öz- } \\
\text { farkın. }\end{array}$ & $\begin{array}{c}\text { Stil } \\
\text { bilinç. }\end{array}$ & $\begin{array}{l}\text { Görün. } \\
\text { bilinç. }\end{array}$ & $\begin{array}{c}\text { Sosyal } \\
\text { anksiyete }\end{array}$ \\
\hline \multicolumn{6}{|l|}{ Kendini Düşünme } \\
\hline Içsel öz-farkındalık & $.78 * *$ & & & & \\
\hline Stil Bilinçliliğgi & $.24 * *$ & $.34 * *$ & & & \\
\hline Görünüm Bilinçliliği & $.31 * *$ & $.37 * *$ & $.73 * *$ & & \\
\hline Sosyal Anksiyete & $-.22 * *$ & $-.25^{*}$ & $-.29 * *$ & $-.23 * *$ & \\
\hline
\end{tabular}

Doğrulayıcı Faktör Analizi. Öz-bilinç Ölçeği’nin Türkçe formunun yapı geçerliği için kullanılan diğer bir yöntem doğrulayıcı faktör analizidir (DFA). DFA kuramsal bir temele dayanarak çeșitli değișkenlerden oluşturulan faktörlerin gerçek verilerle ne derece uyum gösterdiğini değerlendirmeye yönelik bir analizdir. Yani DFA önceden belirlenmiş ya da kurgulanmış bir yapının toplanan verilerle ne derece doğrulandığını incelemeyi amaçlar. Bu araştırmada DFA kullanılmasının nedeni ise orijinal formun faktör yapısının Türk öğrenciler üzerinde yürütülen bu çalışmayla doğrulanıp doğrulanmadığını incelemektir. DFA'da sınanan modelin yeterliğinin belirlenmesi için çok sayıda uyum indeksi kullanılmaktadır (Büyüköztürk ve diğerleri, 2004). Bu çalışmada yapılan DFA için Ki-kare uyum testi (Chi-Square Goodness), İyilik Uyum İndeksi (Goodness of Fit Index, GFI), Düzeltilmiş İyilik Uyum İndeksi (Adjusted Goodness of Fit Index, AGFI), Karşılaştırmalı Uyum Indeksi (Comparative Fit Index, CFI), Normlaştırılmış Uyum Indeksi (Normed Fit Index, NFI), Göreli Uyum İndeksi (Relative Fit Index, RFI), Fazlalık Uyum İndeksi (Incremental Fit Index, IFI) ve Yaklaşık Hataların Ortalama Karekökü (Root Mean Square Error of Approximation, RMSEA) uyum indeksleri incelenmiştir. Bu uyum indekslerinde genelde olduğu gibi GFI, AGFI, CFI, NFI, RFI ve IFI $>.90$ ve RMSEA <.05 ölçüt olarak alınmıștır (Hu \& Bentler, 1999). Yapılan DFA'da elde modelin uyum indeksleri incelenmiş ve Ki-kare değerinin $\left(x^{2}=330.91\right.$, $\mathrm{N}=740, \mathrm{sd}=140, \mathrm{p}=0.00)$ manidar olduğu görülmüştür. Uyum indeksi değerleri ise $\mathrm{RMSEA}=0.047$, NFI $=0.95, \mathrm{CFI}=0.97, \mathrm{IFI}=0.97$, RFI $=0.96$, $\mathrm{GFI}=0.95$ ve $\mathrm{AGFI}=0.93$ olarak bulunmuştur. $\mathrm{Bu}$ uyum indeksi değerleri modelin uyumlu olduğunu ortaya koymaktadır. Modele ilişkin faktör yükleri Şekil 1'de gösterilmiştir.

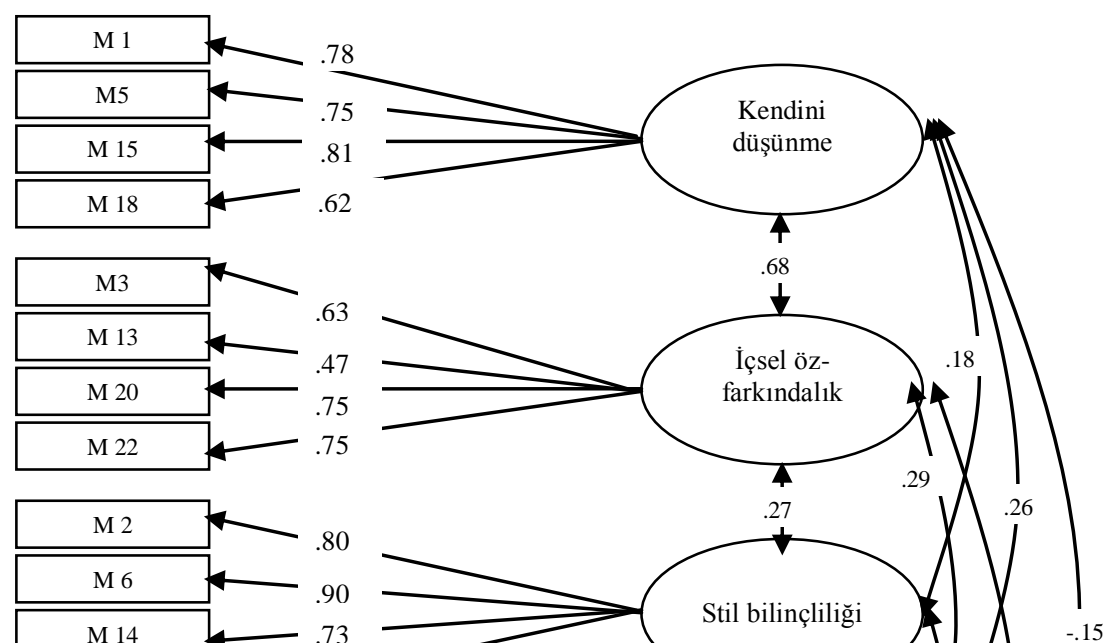




\section{Güvenirlik}

Bu araştırmada Öz-bilinç Ölçeği'nin güvenirlik çalıșmaları olarak iç tutarlılık, test-tekrar test, iki-yarı güvenirlikleri incelenmiştir. Ayrıca düzeltilmiş madde-toplam korelasyonları ve $t$ testi kullanılarak üst $\% 27$ ile alt \%27 grupların madde ortalamaları arasındaki farkların anlamlılığ saptanmıştır. İç tutarlılık katsayıları ölçeğin bütünü için .79, kendini düşünme alt boyutu için .84, içsel öz-farkındalık için .87, stil bilinçliliği için .89 , görünüm bilinçliliği için .91 ve sosyal anksiyete alt boyutu için .87 olarak bulunmuştur.

Diğer bir güvenirlik çalışması olan test-tekrar test güvenirliği için ise uyarlanan ölçek, Sakarya Üniversitesi Eğitim Fakültesi'nde öğrenim gören 205 üniversite öğrencisine 3 haftalık arayla iki kez uygulanmıştır. $\mathrm{Bu}$ uygulamadan elde edilen bulgular Tablo 4 'te görülmektedir. 
Tablo 4. Öz-bilinç Ölçeği test-tekrar test yöntemiyle saptanan güvenirlik katsayıları

\begin{tabular}{lllll}
\hline Faktör & Uygulama & $\bar{X}$ & Ss & $r$ \\
\hline \multirow{2}{*}{ Kendini düşünme } & İlk uygulama & 15.50 & 3.39 & \multirow{2}{*}{.94} \\
& İkinci uygulama & 14.90 & 3.19 & \\
\multirow{2}{*}{ İsel öz-farkındalık } & İlk uygulama & 14.03 & 4.07 & \multirow{2}{*}{.92} \\
& İkinci uygulama & 9.93 & 2.97 & \\
Stil bilinçliliği & İlk uygulama & 7.80 & 2.87 & \multirow{2}{*}{.96} \\
\multirow{2}{*}{ Görünüm bilinçliliği } & İkinci uygulama & 15.17 & 2.99 & \\
& İlk uygulama & 14.60 & 2.90 & \multirow{2}{*}{.91} \\
Sosyal anksiyete & İkinci uygulama & 14.05 & 3.67 & \\
& İlk uygulama & 10.07 & 2.87 & \multirow{2}{*}{.94} \\
\hline
\end{tabular}

Ölçeğin test-tekrar test çalışmasından elde edilen bulgular incelendiğinde güvenirlik katsayılarının beş alt boyut için sırasıyla $.94, .92$, $.96, .91$ ve .94 olduğu görülmektedir. Bu sonuçlar ölçeğin içerdiği alt testlerin, test-tekrar test yöntemiyle belirlenen güvenirlik katsayılarının yüksek olduğunu göstermektedir.

Öz-bilinç Ölçeği'nin madde ayırt ediciliği için madde-toplam korelasyonu ve \%27'lik alt-üst grup karşılaştırmalarına yer verilmiştir. Madde-toplam korelasyonunun hesaplanmasında Pearson momentler çarpımı korelasyon katsayısı, toplam puana göre belirlenmiş \% 27'lik alt-üst grupların madde puanlarının karşılaştırılmasında ise $t$ testi kullanılmıştır. Ölçeğin düzeltilmiş madde-toplam korelasyonlarının .40 ile .70 arasında sıralandığ1, toplam puanlara göre belirlenmiş \%27'lik alt ve üst grupların madde puanlarındaki farklara ilişkin $t(\mathrm{sd}=398)$ değerlerinin ise 17.07 $(p<.001)$ ile $38.34(p<.001)$ arasında değiştiği görülmüştür. Ayrıca en düşük düzeltilmiş madde-toplam katsayısına sahip 16. maddenin çıkartılması durumunda iç tutarlılık katsayısının .72 olduğu görülmektedir. Buna göre çıkartılması durumunda ölçeğin toplam iç tutarlılı̆̆ını önemli oranda değiştirebilecek maddenin olmadığı saptanmıştır. Bulgular Tablo 5'de gösterilmiştir. 
Tablo 5. Öz-bilinç Ölçeği düzeltilmiş madde-test korelasyonları

\begin{tabular}{llllll}
\hline Faktör & $\begin{array}{l}\text { Madde } \\
\text { no }\end{array}$ & $r_{j x}$ & Faktör & $\begin{array}{l}\text { Madde } \\
\text { no }\end{array}$ & $r_{j x}$ \\
\hline \multirow{3}{*}{ Kendini } & 1 & .67 & & 3 & .51 \\
düşünme & 5 & .58 & İçsel & 13 & .40 \\
& 15 & .70 & öz-farkındalık & 20 & .66 \\
& 18 & .50 & & 22 & .66 \\
\hline \multirow{2}{*}{ Stil } & 2 & .49 & & 4 & .48 \\
bilinçliliği & 6 & .61 & Sosyal & 8 & .51 \\
& 14 & .67 & anksiyete & 10 & .50 \\
\hline \multirow{2}{*}{ Görünüm } & 19 & .54 & & 16 & .40 \\
bilinçliliği & 11 & .51 & & & \\
& 17 & .54 & & & \\
\hline
\end{tabular}

Öz-bilinç Ölçeği’nin Türkçe formunda 19 madde bulunmaktadır. Bu nedenle 5'li likert tipi bir derecelendirmeye sahip olan ve "0" dan (hiç uygun değil) "4"e (tamamen uygun) doğru sıralanan bu ölçekten alınabilecek en yüksek puan 76, en düşük puan ise 0 'dır. Ters (reverse) madde bulunmayan ölçeğin her bir alt boyutundan alınan yüksek puan bireyin ilgili alt ölçeğe yönelik öz-bilince sahip olduğunu göstermektedir. Ölçek toplam bir öz-bilinç puanı vermemektedir.

\section{TARTIŞMA ve SONUÇ}

$\mathrm{Bu}$ araştırmanın amacı Fenigstein ve diğerleri (1975) tarafindan geliştirilen ve Mittal ve Balasubramanian (1987) tarafından revize edilen Özbilinç Ölçeği'ni Türkçeye uyarlamak ve ölçeğin geçerlik ve güvenirlik analizlerini yapmaktır. Araştırma grubu sayı bakımından istatistiksel analizlerin gerektirdiği yeterliliktedir. Öz-bilinç Ölçeği'nin Türkçeye uyarlanması titizlikle yürütülen bazı aşamalar sonucunda gerçekleştirilmiştir. Öncelikle ölçek İngilizce uzmanları tarafindan Türkçeye daha sonra ise İngilizceye çevrilmiş ve iki form arasındaki tutarlılık incelenmiştir. $\mathrm{Bu}$ çalışma sonucunda Türkçe denemelik form elde edilmiş ve bu form bir grup yüksek lisans öğrencisine inceletilerek önerileri doğrultusunda, maddelerin ifadelendirilmesi açısından bazı değişiklikler yapılmıştır. Son aşamada ise ölçek, rehberlik ve psikolojik danışmanlık ile ölçme ve değerlendirme alanlarında uzman olan öğretim üyeleri tarafından incelenerek bazı düzenlemeler yapılmıştır. Geçerlik ve güvenirlik çalışmalarına başlamadan önce ölçeğin dilsel eşdeğerliğini incelemek amacıyla Türkçe ve İngilizce form puanları arasındaki korelasyon hesaplanmıştır. Bu çalışma sonucunda elde edilen veriler iki form puanları arasındaki korelasyon katsayılarının 
oldukça yüksek düzeyde olduğunu göstermiştir $(.93, .87, .96, .91$ ve .93$)$. Bu sonuçlar, çeviri maddelerin orijinalleriyle yüksek düzeyde uyum gösterdiğini ve ölçeğin Türkçe formunun özgün ölçek ile eş değer olduğunu ortaya koymaktadır. Ölçeğin dilsel eşdeğerlik çalışmasından elde edilen bulguların yüksek olduğu görüldükten sonra geçerlik ve güvenirlik analizleri yapılmıştır. Özz-bilinç Ölçeği'nin yapı geçerliğini incelemek amacıyla açımlayıcı faktör analizi (AFA) ve doğrulayıcı faktör analizi (DFA) kullanılmıştır. Güvenirlik çalışmaları olarak ise iç tutarlılık ve test-tekrar test, güvenirlikleri ile madde-toplam korelasyonları ve $t$ testi kullanılarak üst $\% 27$ ile alt \%27 grupların madde ortalamaları arasındaki farkların anlamlılığı hesaplanmıştır. Geçerlik ve güvenirlik analizlerinden elde edilen sonuçlar ölçeğin oldukça yüksek düzeyde geçerlik ve güvenirlik ölçülerine sahip olduğunu göstermiştir.

Öz-bilinç Ölçeği'nin AFA sonuçları incelendiğinde, beş faktörlü bir yapıdan oluşan özgün ölçeğin yapısıyla, uyarlanan Türkçe formun faktör yapısının tamamen uyuştuğu ve bu beş faktördeki maddelerin tam olarak örtüştüğü görülmüştür. $\mathrm{Bu}$ beş alt ölçek toplam varyansın \%68'ini açıklamaktadır. Ölçek geliştirme ve uyarlama çalışmalarında açıklanan varyans oranının \%30'un üzerinde olmasının ölçüt alındığı düşünüldüğünde, ölçeğin yap1 geçerliği açısından yeterli olduğu ifade edilebilir. DFA'da ise ölçeğin orijinal faktör yapısının Türk öğrenciler üzerinde yürütülen bu çalışmayla doğrulanıp doğrulanmadığı incelenmiştir. Yapılan DFA'da modelin uyum indeksleri incelenmiş ve Ki-kare değerinin $\left(x^{2}=330.91\right.$, $\mathrm{N}=740, \mathrm{sd}=140, \mathrm{p}=0.00$ ) manidar olduğu görülmüştür. Ölçeğin uyum indeksi değerleri ise RMSEA $=0.047, \mathrm{NFI}=0.95, \mathrm{CFI}=0.97$, IFI $=0.97, \mathrm{RFI}=0.96$, $\mathrm{GFI}=0.95$ ve $\mathrm{AGFI}=0.93$ olarak bulunmuştur. $\mathrm{Bu}$ uyum indekslerindeki ölçütlerin, GFI, AGFI, CFI, NFI, RFI ve IFI için $>.90$ ve RMSEA için ise $<.05$ (Hu \& Bentler, 1999) olduğu dikkate alındığında, ölçeğin orijinal formuyla uyumlu olduğu görülmektedir.

Öz-bilinç Ölçeği'nin Türkçe formunun iç-tutarlılık değerleri ölçeğin bütünü ve alt ölçekler için .79 ile .91 arasında değişmektedir. Bu sonuçlar testte yer alan maddelerin birbirleri ile tutarlı, dolayısıyla iç tutarlık anlamındaki güvenirliğin yüksek olduğunu göstermektedir. Diğer bir anlatımla test maddelerinin her biri testin bütünüyle uyumludur. Ölçeğin test-tekrar test güvenirlik çalışmasında iki uygulama arasındaki korelasyonların beş alt ölçek için .91 ile .96 arasında değiştiği görülmüştür. $\mathrm{Bu}$ iki yöntemle elde edilen güvenirlik katsayıları ölçeğin güvenilir bir ölçme aracı olduğunu göstermektedir.

Madde analizi sonuçları ölçeğin düzeltilmiş madde-toplam korelasyonlarının .40 ile .70 arasında siralandığını ortaya koymuştur. Madde-toplam korelasyonunun yorumlanmasında .30 ve daha yüksek olan maddelerin, bireyleri ölçülen özellik bakımından iyi derecede ayırt ettiği 
(Büyüköztürk, 2004) göz önüne alındığında, ölçeğin madde toplam korelasyonlarının yeterli olduğu görülmektedir. \%27'lik alt ve üst grup puanları arasında yapılan $t$ testi sonuçları tüm maddeler ve alt ölçekler için anlamlı bir farklılık olduğunu ortaya koymuştur.

Geçerlik ve güvenirlik çalışmalarından elde edilen sonuçlara dayanarak ölçeğin Türkçeye uyarlanan formunun bireylerin öz-bilinç düzeylerinin belirlenmesinde geçerli ve güvenilir bir araç olarak kullanılabileceği savunulabilir. Ancak ölçeğin uyum geçerliğini belirlemek amacıyla, özbilinç yapısıyla ilişkili olabilecek psikolojik yapıları değerlendiren ve geçerlik ve güvenirliği kanıtlanmış ölçme araçları ile bu ölçek arasındaki ilişkilerin inceleneceği bir çalışmaya ihtiyaç duyulduğu ortadadır. Son olarak Öz-bilinç Ölçeği'nin faktör yapısının üniversite öğrencileri dışındaki diğer bireyler üzerinde incelenmesinin önemli bir çalışma olacağı söylenebilir. 


\section{KAYNAKLAR}

Anderson, E. M., Bohon, L. M., \& Berrigan, L. P. (1996). Factor structure of the private Self-consciousness Scale. Journal of Personality Assessment, 66, 144-152.

Banos, R. M., Belloch, A., \& Perpina, C. P. (1990). Self-consciousness Scale: A study of Spanish housewives. Psychological Reports, 66, 771774.

Baumeister, R. F., \& Trice, D. M. (1988). Metatraits. Journal of Personality, 56, 571-598.

Bendania, A., \& Abed, A. S. (1997). Reliability and factorial structure of an Arabic translation of the Self-Consciousness Scale. Psychological Reports, 81, 1091-1101.

Bernstein, I. H., Teng, G., \& Garbin, C. P. (1986). A confirmatory factoring of the Self-consciousness Scale. Multivariate Behavioral Research, 21, $459-475$.

Britt, T. H. (1992). The Self-consciousness Scale: On the stability of the three factor structure. Personality and Social Psychology Bulletin, 18, 748-755.

Burnkrant, R. E., \& Page, T. J. (1984). A modification of the Fenigstein, Scheier, and Buss Self-consciousness Scales. Journal of Personality Assessment, 48, 629-637.

Büyüköztürk, Ş. (2004). Veri analizi el kitabı. Ankara: Pegem A Yayınc1lı.

Büyüköztürk, Ş., Akgün, Ö., Kahveci, Ö. \& Demirel, F. (2004). Güdülenme ve Öğrenme Stratejileri Ölçeği'nin Türkçe formunun geçerlik ve güvenirlik çalışması. Kuram ve Uygulamada Eğitim Bilimleri, 4(2), 207-239.

Buss, A. H. (1980). Self-consciousness and social anxiety. San Francisco: Freeman.

Carver, C. S., \& Scheier, M. F. (1978). Self-focusing effects of dispositional self-consciousness, mirror presence, and audience presence. Journal of Personality and Social Psychology, 36, 324-332.

Carver, C. S., \& Scheier, M. F. (1981). The self attention-induced feedback loop and social facilitation. Journal of Experimental Social Psychology, $17,545-568$.

Chang, L. (1998). Factor interpretations of the Self-consciousness Scale. Personality and Individual Differences, 24(5), 635-640.

Cheek, J. M., \& Briggs, S. R. (1982). Self-consciousness and aspects of identity. Journal of Research in Personality, 16, 401-408. 
Comunian, A. L. (1994). Self-consciousness Scale dimensions: An Italian adaptation. Psychological Reports, 74, 483-489.

Conway, M., \& Giannopoulos, C. (1992). Self-esteem and specificity in selffocused attention. The Journal of Social Psychology, 133(1), 121-123.

Conway, M., Giannopoulos, C., Csank, P., \& Mendelson, M. (1993). Dysphoria and specificity in self-focused attention. Personality and Social Psychology Bulletin, 19(3), 265-268.

Creed, A. T., \& Funder, D. C. (1998). The two faces of private selfconsciousness: Self report, peer-report, and behavioral correlates. European Journal of Personality, 12, 411-431.

Fenigstein, A., Scheier, M. F., \& Buss, A. H. (1975). Public and private selfconsciousness: Assessment and theory. Journal of Consulting and Clinical Psychology, 43, 522-527.

Grob, A. (1995). Subjective well-being and significant life-events across the life span. Swiss Journal of Psychology, 54, 3-18.

Heineman, W. (1979). The assessment of private and public selfconsciousness: A German replication. European Journal of Social Psychology, 9, 331-337.

Hu, L. T., \& Bentler, P. M. (1999). Cutoff criteria for fit indexes in covariance structural analysis: Conventional criteria versus new alternatives. Structural Equation Modeling, 6, 1-55.

Ingram, R. E. (1990). Self-focused attention in clinical disorders: Review and a conceptual model. Psychological Review, 107, 156-176.

Lennox, R., Welch, L., Wolfe, R., Zimmerman, B., \& Dixon, W. (1987). Assessment of self- consciousness. Representative Research in Social Psychology, 17, 53-73.

Lindwall, M. (2004). Factorial structure and invariance across gender of the Swedish Self-Consciousness Scale. Journal of Personality Assessment, 82(2), 233-240.

Mittal, B., \& Balasubramanian, S. K. (1987). Testing the dimensionality of the Self-consciousness Scales. Journal of Personality Assessment, 51, 53-68.

Nystedt, L., \& Ljungberg, A. (2002). Facets of private and public selfconsciousness: Construct and discriminant validity. European Journal of Personality, 16, 143-159.

Nystedt, L., \& Smari, J. (1989). Assessment of the Fenigstein, Scheier, and Buss Self-consciousness Scale: A Swedish translation. Journal of Personality Assessment, 53, 342-352. 
Piliavin, J. A., \& Charng, H. (1988). What is the factorial structure of the private and public self-consciousness scales? Personality and Social Psychology Bulletin, 14, 587-595.

Realo, A., \& Allik, J. (1998). The Estonian Self-consciousness Scale and its relation to the five-factor model of personality. Journal of Personality Assessment, 70, 109-124.

Scheier, M. F., \& Carver, C. S. (1977). Self-focused attention and the experience of emotion: Attraction, repulsion, elation, and depression. Journal of Personality and Social Psychology, 35, 625-636.

Scheier, M. F., \& Carver, C. S. (1985). The Self-consciousness Scale: A revised version for use with general populations. Journal of Applied Social Psychology, 15, 687-699.

Scheier, M. F., Buss, A. H., \& Buss, D. M. (1978). Self-consciousness, selfreport of aggressiveness and aggression. Journal of Research in Personality, 12, 133-140.

Shek, D. T. L. (1994). Assessment of private and public self-consciousness: A Chinese replication. Journal of Clinical Psychology, 50, 341-348.

Tabachnick, B. G., \& Fidell, L. S. (1996). Using multivariate statistics. New York: HarperCollins College Publishers.

Teixeira, M. A. P., \& Gomes, W. B. (1995). Self-consciousness Scale: A Brazilian version. Psychological Reports, 77, 423-427.

Turner, R. G. (1978). Effect of differential request procedures and selfconsciousness. Journal of Research in Personality, 12, 431-438.

Vleeming, R. G., \& Engelse, J. A. (1981). Assessment of private and public self-consciousness: A Dutch replication. Journal of Personality Assessment, 45, 385-389.

Watson, P. J., \& Biderman, M. D. (1993). Narcissistic personality inventory factors, splitting, and self-consciousness. Journal of Personality Assessment, 61, 41-57.

Watson, P. J., Milliron, J. T., \& Morris, R. J. (1995). Social desirability scales and theories of suicide: Correlations with alienation and selfconsciousness. Personality and Individual Differences, 18, 701-711.

Watson, P. J., Hickman, S. E, Morris, R. J., Stutz, N. L., \& Whiting, L. (1994). Complexity of self-consciousness subscales: Correlations of factor with self-esteem and dietary restraint. Journal of Social Behavior and Personality, 9, 761-774.

Watson, P. J., Morris, R. J., Ramsey, A., Hickman, S. E., \& Waddell, M. G. (1996). Further contrasts between self-reflectiveness and internal state awareness factors of private self-consciousness. Journal of Psychology, 130, 183-192. 